\title{
INTERNATIONALIZATION PROCESS OF FIRMS FROM DEVELOPING COUNTRY: AN EMPIRICAL EVIDENCE OF UAE FAMILY BUSINESS FIRMS
}

\author{
Muhamad Sham Shahkat $\mathrm{Ali}^{1 *}$, Amiruddin Ahamat $^{2}$ \\ ${ }^{1}$ Dr. Abu Dhabi University, UNITED ARAB EMIRATES, muhamad.sham@adu.ac.ae \\ ${ }^{2}$ Dr. Universiti Teknikal Malaysia Melaka, MALAYSIA, amiruddin@utem.edu.my \\ ${ }^{*}$ Corresponding author
}

\begin{abstract}
There are many reasons behind the internationalization expansion of family businesses. This study provides an understanding of the international expansion strategy of family businesses in the United Arab Emirates (UAE) in comparison to other countries. The purpose of this paper is to investigate the internationalization strategy for family businesses, key driving factors and the major barriers that could restrict United Arab Emirates family businesses progress. Based on the objective of the study, this paper encompasses both qualitative and quantitative research. The sample of this study includes 20 managers of top 10 family businesses in UAE. The findings indicate that most of the participants $(80 \%)$ are interested in the internationalization process to expand their operations. To remain competitive, UAE policymakers should consider entrepreneurship education and business initiative to stimulate entrepreneurship activities both at the local and national levels.
\end{abstract}

Keywords: Internationalization, Family Business, Strategic Management.

\section{INTRODUCTION}

Choosing the right entry mode for international expansion is a critical managerial decision and can have significant and far-reaching consequences for a firm's performance and survival (Lu and Beamish, 2001; Bradley and Gannon, 2000). According to Chen and Mujtaba (2007), the methods of international market entry are understood to vary in three major aspects: (a) cost as resource commitment; (b) control as level of ownership; and (c) risk related to the level of resources committed and the complexity of the environment entered (Chen and Mujtaba, 2007).

\subsection{Literature Review}

According to Treadgold (1988), there are three types of entry strategy for corporations in international 
markets. The first strategy is the entry strategy that affords a high degree of control, for instance wholly owned, and acquisition. The second type of strategy is a medium degree of cost and control, such as joint venture, and the third type of strategy is the low cost of control strategy, such as franchise arrangements.

\subsubsection{Internationalization Strategy of Family Businesses}

According to Walton (2007), the main purpose of diversification is to allow the firm to grow by diversifying into new businesses by developing new products for new markets. Generally, internationalization refers to the most critical strategy used by any firm. The main reason behind internationalization is to own growing market globalization, including family businesses (FB) or family Small and Medium Enterprises (SMEs) that focused on the domestic market in the past. Various countries have been identified in relation to the use of the internationalization strategy, but limited research has been done to evaluate the strategy with respect to FBs in the United Arab Emirates. Fernández and Nieto [2005] posit that international expansion is usually based on the opportunities that were present in international markets which can be exploited to achieve a competitive edge. Fernández and Nieto [2005], and Shahid et al. [2014] further explained that small and medium FBs face various issues in relation to internationalization. This study aims to examine the internationalization strategy of the FB in the UAE, in comparison to other countries.

\subsubsection{Modes of Internationalization by Family Business}

According to Dimitratos (2004), there are five general and most common types of strategies that a firm can use in internalization with each having relatively uniform characteristics and consequences for the firm. He classified them as: exporting, licensing or franchising, joint ventures, strategic alliances and subsidiaries or acquisitions. Plakoyiannaki, Pavlos Kampouri, Stavraki and Kotzaivazoglou (2014) stated that internationalization refers to a set of business activity that could extend over international markets with the objective to create value for the firm as well as its customers (Bell, J., Crick, D., \& Young, S. (2004). In addition, the entry mode provides an overview of the degree to which local firms initiate irreversible moves in the foreign markets. Resource limitation and high risk make it difficult for FBs to switch from one entry mode to another. Modes of entry have been divided into different classes based on of low or high international commitment in the international markets. For instance, exporting represents a low commitment entry mode as the local firm can disengage from international markets without issue and financial loss. Licensing, as well as joint venture, provide an overview of medium commitment entry modes as the local firm shares risks with its international partner. An entry mode in the international market such as a wholly owned subsidiary like FDI needs high commitment with respect to resources and are linked to higher failure costs compared to exporting/licensing (Plakoyiannaki et al. (2014). Another mode of entry in the international market is a strategic alliance in which trust is a key factor (Fadol, Y.Y., \& Sandhu, M. A., 2013)

Sirmon and Hitt (2003) distinguished five unique characteristics that differentiate family firms from non-family firms, namely human capital, social capital, survivability capital, patient capital and characteristic governance structures. Plakoyiannaki et al. (2014) provided a notion about FB internationalization in the context of Greek Apiculture. According to them, the potential of digital media had been identified by the Apivita, Greek Beekeeping Center and Bio Honey Abaton. They used, chose and competed for geographically distant markets with the help of Information Technology (IT). These firms are labeled as 'e-born' global FBs. Through the digital entry mode, FBs described earlier developed the versatility in relation to international opportunities and enabled themselves to increase their knowledge base. Apivita (family business) chose entry modes such as direct export through a sales representative to enter the Spain market, FDI as wholly own subsidiary to enter the Japanese market, and e-commerce to penetrate into the USA market.

Two other scholars, Daszkiewicz and Wach (2014) provided an overview of entry modes of family firms in Poland. The authors described that FBs are expanding their operations into international markets not only for survival reason but also to grow in the competitive business environment. Nevertheless, the internationalization of FBs is processed differently than a firm with a different ownership structure. The results indicated that Poland FBs had a more active approach to internationalization, whereas non-family firms had reactive motives. In addition, FBs are market seekers at higher rates than non-family firms. The most reputed entry mode in international markets in Poland is direct exporting and sub-contracting. In Poland, there are no differences among FBs and non-FBs with respect entry modes to enter international markets (Fadol, Y. Y., \& Sandhu, M. A, 2013)

\subsubsection{International Expansion Strategy of Japanese Firms}

Chang (1995) studied the impact of firms' building capability in operating their operation in the international market through the sequential foreign entry process. From the perspective of resource and capability, it was found that the Japanese electronics firms learn from their own experience in the international market (Fadol, Y. Y., \& Sandhu, M. A, 2013). To reduce the risk of failure, Japanese firms enter their key businesses into 
the international markets along with those in which they have a competitive edge over local firms. They learn from the early entries of firms to initiate further entry into areas in which they have next high-level competitive edge. With the accumulation of learning, they overcome the issues intrinsic to foreignness. The process of capability building by the Japanese firms in international markets aligns very well with the process of diversified entry. All in all, Japanese firms make incremental and sequential investments in the international market by moving from initial to further investment instead of acquisition or 'greenfield' investments.

One of the examples of internationalization strategy that Japanese firms use is the acquisition of a Japanese firm in India's Ranbaxy. In 2008, Japan's second-biggest pharmaceutical company (Daiichi Sankyo) agreed to purchase Ranbaxy Laboratories. The firm focused on the strategy the Japanese use, which is a sequential investment and not full-scale acquisition, to enter the Indian market. The firm acquired Ranbaxy (family business) through a series of share purchasing based on different classes, such as share acquisition through an open offer, shares allotment on preferential basis, and share acquisition from the Singh family with a total value of 268,711,323 [Fadol, Y. Y., \& Sandhu, M. A, 2013).

\subsubsection{International Expansion Strategy of Japanese Firms}

The Middle East is considered a highly diverse region as the diversities in the region are not limited to languages, ethnicities, and religion. The countries in the region have different ranges of political and economic systems (Metwally, M. M., 2004). Various reputed multinational retailers invested in the region by conducting businesses like Sweden's Ikea and Spain's Zara. In addition, business-to-business service firms also operate in the region like the American management consulting firm, Watson Wyatt Worldwide, and India's IT giant, Wipro Limited (Mellahi, K., Demirbag, M., \& Riddle, L, .2011). In the Middle East, including Saudi Arabia, UAE, Kuwait, Bahrain, and others, MNEs provide a full range of entry choices ranging from exporting to fully owned subsidiaries. The most popular entry modes include franchising and joint ventures. In the Middle East, including the UAE, the strategy of a wholly owned subsidiary to enter the international market is limited (Mellahi, K., Demirbag, M., \& Riddle, L, .2011).

Mellahi et al. (2011) stated that international joint ventures are of foremost importance in the oil extraction industries, manufacturing and banking sectors in the Middle East including UAE. Franchising, on the other hand, is the key entry mode in the food, retail, and hospitality industries. For example, most emerging economies business groups dictate the business landscape in the Middle East. This ranges from strong families in the Gulf States (UAE) to strong charitable religious foundations in Iran (Bonyads). For instance, one of the most powerful business groups (Alshaya), a private Kuwait FB and one of the leading and influential retail franchisees in the Middle East, obtained a license and made franchise agreements with key household retail brands like Next, TopMan, Body Shop, Starbucks, Dorothy Perkins, Miss Selfridge and Debenhams (Mellahi, K., Demirbag, M., \& Riddle, L, .2011)

\subsubsection{International of ARCAPITA, Bahrain, DP World of UAE and SAOG of Oman}

One of the examples of successful internationalization of Middle East's FBs is Arcapita. Arcapita as a young Islamic financial bank was successfully internationalized despite the various financial banks in the Arabian Gulf that have failed to identify the opportunity. Islamic investment banking is a new concept as it is a niche market, but Arcapita exploited this opportunity and internationalized itself in a short time. The company raised funds and used the strategy of acquisition and diversification. It diversified its products and services and uses funds to invest in the USA, Europe, Middle East and Asia through an acquisition (Mostafa Khan, G., \& Jamal Uddin, S., 2013). Mostafa Khan and Jamal Uddin (2013) listed some of the famous internationalization of family-owned businesses in the UAE, such as DP World and Istihmar. DP World acquired a terminal portfolio of CSX World Terminals as well as P\&O Ports. The company increased its presence in China, Hong Kong, South Asia, Australia, America, and Europe (Notteboom, T., 2011). Khan (2012) provided a case of an Oman-based FB named Renaissance Service SAOG, which has internationalized its operations successfully. The company is an oil and gas industry service company and is listed in the Oman Muscat Securities Market. The founder of the company showed courage and moved to internationalize the company's operations by acquiring all shares of Norsk Offshore Catering in Norway in 2005 to enter the European oil and gas service market. In 2007, a Topaz and Saudi company (Gentas Ltd) made a joint venture to meet the demand in Saudi Arabia. In 2008, Topaz Energy and Marine acquired Doha Marine Services (DMS). It was a major event for the company to increase in size and spread geographically. The company grew significantly through mergers and acquisitions (M\&A) enabled them to be a leading company with global presence and positive financial and marketing performance (Khan, G. M. (2012).

\subsubsection{Family Businesses in Gulf Countries, and Internationalization Strategies}

Chaudhry and Crick (2003) provided a notion that there is no single definition of a family business (FB). According to them, a family business can be referred to an enterprise with more than two family members or 
they have $15 \%$ or more shares; they are employees of the business and have an intention of retaining control of the firm in future. In contrast, Sharma (2003) stated that FB refers to a business managed with the intention to form and follow the vision of the business held by the alliance controlled by the members of the same family in a way that is sustainable across the family's generations. According to Shanker and Astrachan (1996), the definition of FB depends on various criteria such as the percentage of ownership, control of voting, power on strategic direction, and active management of the family members.

FBs from GCC, including UAE, share similar cultural, economic, social, religious, demographic and political characteristics. FBs play a key role in the growth of countries' economies, especially in terms of creating job opportunities. The institutional support mechanism to encourage the successes and failures of FBs is vital (A. Ahamat and S.C. Chong, 2014). In Dubai, there are about 30,769 family companies with 560,000 workers that contributed AE208 billion to the firms' turnover in 2004. It has been identified that about $90 \%$ of the commercial activity in GCC is managed and controlled by FBs. Moreover, more than $75 \%$ of companies in the Middle East are family-owned. Some of the FBs in GCC as described earlier are big multi-national conglomerates with approximately 30 businesses and operations in 40 countries. In UAE, FBs are allowed to be public and have 70\% stock. Table 1 identified the top ten families in GCC in 2008 [19] services to Oman. In addition, it expanded its operations in Qatar and Kuwait through different lines by using the diversification strategy. By 2010, the company had entered many industries like shipping, transportation and hotel franchises across GCC countries (Kontinen, T., \& Ojala, A., 2010).

Zain and Kassim (2012) identified the strategies FBs in GCC used to expand their operations in a newly globalized developing economy. This data was gathered from the Qatar Chamber of Commerce and Industry in Qatar (one of the GCC states). The results provided a notion that availability of opportunities extracted from globalization is more important to FBs in GCC countries like UAE and Qatar than threats. Moreover, the availability of networks creates an opportunity for the FBs to expand operations. Last but not the least, the availability of funds also affect the firms' level of readiness to face issues and forces of globalization and impacts their decision making to make new strategies to face those forces and challenges.

Hvidt (2009), Nasra and Dacin (2010) corroborated the development process in Dubai, UAE through the internationalization of family and non-family businesses. Dubai has made various FDI over last few years in every industry ranging from aircraft manufacturers to Las Vegas casinos. Between 2006 and 2007, Dubai spent about 49 billion US dollars on acquisitions. Non-family business internationalization in Dubai includes Dubai Internet City (DIC) that has a 33\% share in Europe, 27\% in the Middle East, $15 \%$ in America, $4 \%$ in Asia Pacific, and $2 \%$ in Africa through acquisitions as a home for Microsoft, Cisco Systems, IBM, HP and Sun Microsystems. Family-owned businesses include DP World as described earlier. In 2006, the company through the acquisition of international business bought the London-based Peninsular and Oriental Steam Navigation Company for \$6.8billion (Hvidt, M., 2009).

Another example of the internationalization of an FB in UAE includes the Zayed Al Hussaini Group. The business was established by the grandfather of Zayed Al Hussaini. After connecting with the MNCs, Zayed joined two lines of his business under the name of Al Hussaini Group. To exploit the opportunities in international markets, the company expanded its operations to Oman through a strategy of diversification (Kontinen, T., \& Ojala, A., 2010). The company successfully expanded transportation and financial services to Oman. In addition, it expanded its operations in Qatar and Kuwait through different lines by using the diversification strategy. By 2010, the company had entered many industries like shipping, transportation and hotel franchises across GCC countries (Kontinen, T., \& Ojala, A., 2010).

\section{METHODOLOGY}

Ahamat and Chong (2015) claimed that a research methodology is an element that allows researchers to systematically frame the study in order to address all the research questions and at the same time to achieve the research aims. Della Porta (2014) pointed out that research refers to a collaborative human activity in which social reality is observed on the objective basis with the focus on gaining a valid understanding of it. Generally, there are three major types of research methods; qualitative research, quantitative research, and mixed research. Creswell (2013) stated that a qualitative research method is an approach in which the researchers make knowledge claims based on constructivist perspectives. It holds different meanings based on the person's experiences which have been developed socially and historically with the focus to design a theory of pattern. Hall (2008) indicated that the quantitative approach is based on the positivist perspective to develop the focus of a study on observable facts. The mixed methodology is the combination of the qualitative and quantitative approaches. For this study, the quantitative research method was used to collect the primary data. The population of the study was the top FBs in UAE. The sample of the study was 20 managers of the top $10 \mathrm{FBs}$ in UAE. The sample was drawn with the help of random sampling to reduce bias and error and give equal chance to every participant. The primary data was collected through a 
questionnaire, while the secondary data was collected through books, journals, reports and websites. This instrument was used because it was an inexpensive way to collect data and was feasible in terms of convenience. The questionnaire included 10 close ended questions to evaluate the situation of FBs in UAE that uses different strategies to internationalize their businesses. An informed consent was sent to the participants of the study to provide them assurance that their data will be kept private and their confidentiality will not be compromised. The collected data was then compiled and analyzed.

\section{RESULTS AND DISCUSSION}

The result indicated that most of the participants $(80 \%)$ are interested in the internationalization process to expand their operations. On the other hand, $20 \%$ showed no interest in internationalization. The results were supported by Jabeen and Katsioloudes (2013) and Shahid et al. (2014). The second element examined the factors that influence the FBs to internationalize their businesses. From the response, $20 \%$ of the participants identified that they internationalize their businesses due to globalization, $10 \%$ stated the growth factor, $20 \%$ described factors of competition, $10 \%$ indicated the factor of increasing market share and $40 \%$ stated that they internationalize their businesses due to all these factors.

The finding is supported by Fernández and Nieto (2005) and Kontinen and Ojala (2014). The third element investigated the perspectives used by FBs to internationalize their businesses. $40 \%$ of the participants stated that they used the economic perspective to internationalize their FBs. $20 \%$ indicated the process perspective, $20 \%$ the rational perspective and $20 \%$ on the capabilities perspective. The fourth context examined the modes of internationalization. $10 \%$ of the participants stated joint venture, $10 \%$ on merger and acquisition, $10 \%$ on franchising, $10 \%$ on exporting, $10 \%$ on wholly-owned subsidiaries, and $50 \%$ said all types of modes are used to internationalize FBs. This result reflects the notions of Fadol and Sandhu (2013), Bell et al. (2004), and Plakoyiannaki et al. (2014). The fifth element identified the strategy used by Japanese firms to internationalize the FBs. $60 \%$ of the participants indicated that Japanese firms use the sequential acquisition to internationalize their FBs. $20 \%$ said they used full-scale acquisition whereas another $20 \%$ said merger and acquisition. Only 10\% said franchising and exporting as supported by Graves (2008). The sixth element investigated the strategy used by Middle East FBs (such as in Bahrain and Oman). In response, $20 \%$ stated that these countries use joint ventures, $20 \%$ stated franchising, and $60 \%$ stated that they use both. Mellahi et al. (2011), Mostafa Khan and Jamal Uddin (2013) supported these results. The last factor examined the most popular strategy used by UAE FBs. $40 \%$ of the participants stated that UAE FBs use joint ventures to expand their operations in the international markets, $20 \%$ stated franchising, and $40 \%$ stated acquisitions. The results are similar to the previous studies conducted by Hvidt (2009), Nasra and Dacin (2010), and Shahid et al. (2014).

The result indicated that most of the participants $(80 \%)$ are interested in the internationalization process to expand their operations. On the other hand, $20 \%$ showed no interest in internationalization. The results were supported by Jabeen and Katsioloudes [26] and Shahid et al. (2014)]. The second element examined the factors that influence the FBs to internationalize their businesses. From the response, $20 \%$ of the participants identified that they internationalize their businesses due to globalization, $10 \%$ stated the growth factor, $20 \%$ described factors of competition, $10 \%$ indicated the factor of increasing market share and $40 \%$ stated that they internationalize their businesses due to all these factors. The finding is supported by Fernández and Nieto [2], and Kontinen and Ojala (2010). The third element investigated the perspectives used by FBs to internationalize their businesses. $40 \%$ of the participants stated that they used the economic perspective to internationalize their FBs. $20 \%$ indicated the process perspective, $20 \%$ the rational perspective and $20 \%$ on the capabilities perspective. The fourth context examined the modes of internationalization. $10 \%$ of the participants stated joint venture, $10 \%$ on merger and acquisition, $10 \%$ on franchising, $10 \%$ on exporting, $10 \%$ on wholly-owned subsidiaries, and $50 \%$ said all types of modes are used to internationalize FBs. This result reflects the notions of Fadol and Sandhu (2013), Bell et al. (2004), and Plakoyiannaki et al. (2014). The fifth element identified the strategy used by Japanese firms to internationalize the FBs. $60 \%$ of the participants indicated that Japanese firms use the sequential acquisition to internationalize their FBs. 20\% said they used full-scale acquisition whereas another $20 \%$ said merger and acquisition. Only $10 \%$ said franchising and exporting as supported by Graves [27]. The sixth element investigated the strategy used by Middle East FBs (such as in Bahrain and Oman). In response, 20\% stated that these countries use joint ventures, $20 \%$ stated franchising, and $60 \%$ stated that they use both. Mellahi et al. [12], Mostafa Khan and Jamal Uddin (2013) supported these results. The last factor examined the most popular strategy used by UAE FBs. $40 \%$ of the participants stated that UAE FBs use joint ventures to expand their operations in the international markets, $20 \%$ stated franchising, and $40 \%$ stated acquisitions. The results are similar to the previous studies conducted by Hvidt (2009), Nasra and Dacin (2010) and Shahid et al. (2014). 


\section{CONCLUSION}

It can be concluded from the above findings and discussion that internationalization is now very important for every type of business like FB. Nevertheless, globalization has shaped the way the business is run in the competitive environment. The major reasons that restricted the UAE FBs to internationalize the businesses include fear of losing control, culture, and lack of resources, skills, and capabilities. Hence, it is a challenge for UAE FBs to adopt abrupt structural business and cultural changes in response to globalization and internationalization. Ahamat and Chong (2015) indicated that the process of discovering and creating potential business opportunities for any new venture creation are critical in shaping entrepreneurial actions and the intent to create any potential business opportunities.

Thus, to remain competitive, UAE policymakers may consider entrepreneurship educations and business initiatives to stimulate entrepreneurship activities both at the local and national levels. This could be done by promoting entrepreneurship at schools, colleges, and universities in the UAE to develop strong entrepreneurship ecosystems within the community. Further research on FBs in UAE employing personal observation and in-depth interviews across different generations would be useful to examine the questions of FB trans-generational changes and its impact on the UAE economy. Furthermore, this study could benefit more by employing an interpretive inquiry. An interpretive inquiry aims to characterize how people experience the world, the ways they interact with each other, and the settings in which these interactions take place (2013). This includes the interpretation of meaningful human expressions, written, verbal and/or physical, involving namely human and social actions (2008).

\section{REFERENCE LIST}

Bell, J., Crick, D., \& Young, S. (2004). Small firm internationalization and business strategy an exploratory study of 'knowledge-intensive'and 'traditional'manufacturing firms in the UK. International Small Business Journal, 22(1), 23-56.

Bradley F., and Gannon M. (2000). Does the firm's technology and marketing profile affect foreign market entry? Journal of International Market, Vol. 8(4), pp. 12-36.

Claver, E., Rienda, L., \& Quer, D. (2009). Family firms' international commitment: The influence of familyrelated factors. Family Business Review, 22 (2), 125-135.

Chang, S. J. (1995). International expansion strategy of Japanese firms: Capability building through sequential entry. Academy of Management journal, 38(2), 383-407.

Chen S.F., and Hennart J.F. (2002). Japanese investors' choice of joint ventures versus wholly-owned subsidiaries in the US: the role of market barriers and firm capabilities, Journal of International Business Studies, Vol. 33(1), pp. 1-18.

Daszkiewicz, N., \& Wach, K. (2014). Motives for going international and entry modes of family firms in Poland. Journal of Intercultural Management, 6(2), 5-18.

Fadol, Y. Y., \& Sandhu, M. A. (2013). The role of trust on the performance of strategic alliances in a crosscultural context: A study of the UAE. Benchmarking: An International Journal, 20(1), 106-128.

Fernández, Z., \& Nieto, M. J. (2005). Internationalization strategy of small and medium-sized family businesses: Some influential factors. Family Business Review, 18(1), 77-89.

Shahid, A., Bodolica, V., \& Spraggon, M. (2014). Zayed Al Hussaini Group: The road ahead for the family business in the UAE. Emerald Emerging Markets Case Studies, 4(1), 1-23.

Kontinen, T., \& Ojala, A. (2010). The internationalization of family businesses: A review of extant research. Journal of Family Business Strategy, 1(2), 97-107.

Paul, J., \& Bhawsar, P. (2011). Japanese acquisition in India's Ranbaxy. Competitiveness Review: An International Business Journal, 21(5), 452-470.

Plakoyiannaki, E., Pavlos Kampouri, A., Stavraki, G., \& Kotzaivazoglou, I. (2014). Family business 
IJASOS- International E-Journal of Advances in Social Sciences, Vol. IV, Issue 10, April 2018

internationalisation through a digital entry mode. Marketing Intelligence \& Planning, 32(2), 190-207.

Lu J.W., and Hebert L. (2005). Equity control and the survival of international joint ventures: a contingency approach, Journal of Business Research, Vol. 58(6), pp. 736-45.

Metwally, M. M. (2004). Impact of EU FDI on economic growth in Middle Eastern countries. European Business Review, 16(4), 381-389.

Mellahi, K., Demirbag, M., \& Riddle, L. (2011). Multinationals in the Middle East: Challenges and opportunities. Journal of World Business, 46(4), 406-410.

Mostafa Khan, G., \& Jamal Uddin, S. (2013). Internationalization of an Islamic investment bank: opportunities and challenges of Arcapita. Journal of Strategy and Management, 6(2), 160-179

Notteboom, T. (2011). Current issues in shipping, ports and logistics. USA: Asp/Vubpress/Upa.

Khan, G. M. (2012). Internationalization of an entrepreneurial services company from the Arabian Gulf: The case of renaissance services SAOG. International Journal of Business and Management, 7(8), 33.

Chaudhry, S., \& Crick, D. (2003). Small Asian-owned retail businesses in the UK: an exploratory investigation. Marketing Intelligence \& Planning, 21(6), 346-356.

Sharma, P. (2004). An overview of the field of family business studies: Current status and directions for the future. Family business review, 17(1), 1-36.

Shanker, M. C., \& Astrachan, J. H. (1996). Myths and realities: Family businesses' contribution to the US economy-A framework for assessing family business statistics. Family Business Review, 9(2), 107123.

Zain, M., \& Kassim, N. M. (2012). Strategies of family businesses in a newly globalized developing economy. Journal of Family Business Management, 2(2), 147-165.

Hvidt, M. (2009). The Dubai model: An outline of key development-process elements in Dubai. International Journal of Middle East Studies, 41(03), 397-418.

Treadgold A., (1988). Retailing without frontiers: the emergence of transnational retailers, International Journal of Retail and Distribution Management, Vol. 16(6), pp. 8-12.

Nasra, R., \& Dacin, M. T. (2010). Institutional arrangements and international entrepreneurship: the state as institutional entrepreneur. Entrepreneurship Theory and Practice, 34(3), 583-609.

Ahamat, A. \& Chong, S.C., "Multi-Methodological Approaches in Qualitative Entrepreneurship Research, International Business Management," Vol 9, no. (4), pp. 601-612, 2015.

Della Porta, D. (2014). Methodological practices in social movement research. USA: Oxford University Press.

Creswell, J. W. (2013). Research design: Qualitative, quantitative, and mixed methods approaches. UK: Sage.

Hall, R. (2008). Applied social research: Planning, designing and conducting real-world research. Australia: Macmillan Education AU.

Jabeen, F., \& Katsioloudes, M. I. (2013). Just Falafel: a success story of an international expansion. Emerald Emerging Markets Case Studies, 3(2), 1-12.

Graves, C., \& Thomas, J. (2008). Determinants of the internationalization pathways of family firms: An examination of family influence. Family Business Review, 21(2), 151-167.

A. Ahamat and S.C. Chong, Assessment of the Factors Influencing Entrepreneurs on The Biotechnology Business Venture. Proceedings of the 24th International Business Information Management Association Conference - Crafting Global Competitive Economies: 2020 Vision Strategic Planning and Smart Implementation, pp. 2171-2177, 2014.

A. Ahamat, Entrepreneurial opportunity creation in the biotechnology industry in Malaysia. Sheffield: University of Sheffield, 2013.

L.D. Parker, Interpreting interpretive accounting research. Critical Perspectives on Accounting, 19(6): 909914, 2008. 